\title{
EFEKTIFITAS MEDIA VIDEO TUTORIAL PENATALAKSANAAN ASI EKSLUSIF TERHADAP KETERAMPILAN IBU DALAM MENYUSUI
}

\author{
Effectiveness of Media Video Tutorial on Management of Exclusive \\ Breastfeeding Against Skills of Mothers In Breastfeeding \\ Elin Supliyani ${ }^{1 *}$, Fauzia Djamilus ${ }^{1}$ \\ ${ }^{1}$ Program Studi Kebidanan Bogor Poltekkes Kemenkes Bandung \\ *Email: elinsupliyani@yahoo.co.id
}

\begin{abstract}
The coverage of achieving exclusive breastfeeding in West Java in 2014 only reached 33.7\%. This figure is far below national coverage. Achieving breastfeeding success requires knowledge of the proper management of breastfeeding, such as correct breastfeeding techniques, how to express milk, correct storage of breast milk. Health education for breastfeeding mothers aims to increase knowledge and skills in milking and storing the right milk. In order for health education to be provided more effectively and in accordance with the goals and objectives, it is necessary to have media that are interesting and more easily accepted by the target. One of the media that can be used is video tutorial media. Video tutorial media rely on hearing and vision of the target. Thus it is very important to know the effect of health education with video tutorial media on improving the knowledge and skills of mothers in the management of exclusive breastfeeding. This study uses a pre-experimental one group pre-test post-test design, conducted in the area of Bogor City Health Center. Sampling was done by purposive sampling conducted on 26 respondents in the intervention group and 26 respondents in the control group. Variables were measured using a pre-test post-test instrument before and after the educational treatment was given with a video tutorial media about the management of exclusive breastfeeding. Statistical tests use the one sample $t$ test. The results showed that there was a significant increase in knowledge and skills of mothers in breastfeeding after being educated through video tutorial media about the management of exclusive breastfeeding with a $p$ value $<0.005$. Health education with exclusive breastfeeding management video tutorials is effective in increasing mother's knowledge and skills in breastfeeding. It is hoped that this video can be used as a media in educating pregnant women and breastfeeding mothers.
\end{abstract}

Keywords: video tutorial, exclusive breastfeeding

\begin{abstract}
ABSTRAK
Cakupan ASI Eksklusif di Jawa Barat pada tahun 2014 baru mencapai 33,7\%. Angka ini jauh di bawah cakupan nasional. Untuk mencapai keberhasilan menyusui membutuhkan pengetahuan tentang penatalaksanaan pemberian ASI yang benar, seperti teknik menyusui, cara memerah ASI, penyimpanan ASI yang benar. Pendidikan kesehatan bagi ibu menyusui bertujuan untuk meningkatkan pengetahuan dan keterampilan dalam memerah ASI dan menyimpan ASI yang tepat. Agar pendidikan kesehatan yang diberikan lebih efektif, dan sesuai dengan sasaran dan tujuan, maka diperlukan media yang menarik dan lebih mudah diterima sasaran. Salah satu media yang dapat digunakan adalah media video tutorial. Media video tutorial mengandalkan pendengaran dan penglihatan target. Oleh karena itu sangat penting untuk mengetahui
\end{abstract}


pengaruh pendidikan kesehatan dengan media video tutorial terhadap peningkatan keterampilan ibu dalam penatalaksanaan ASI eksklusif. Penelitian ini menggunakan rancangan pre-eksperimental one group pre-test post-test design yang dilaksanakan di wilayah kerja Puskesmas Kota Bogor. Pengambilan sampel dilakukan secara purposive sampling yang dilakukan rehadap 26 responden kelompok intervensi dan 26 responden kelompok kontrol. Variabel diukur menggunakan instrumen pre-test posttest sebelum dan sesudah diberikan edukasi dengan media video tutorial tentang penatalaksanaan ASI Eksklusif. Uji statistik menggunakan uji one sample $t$ test. Hasil penelitian menunjukkan bahwa terdapat peningkatan yang signifikan pada keterampilan ibu dalam menyusui setelah diberikan edukasi melalui media video tutorial tentang manajemen ASI Eksklusif dengan nilai $p<0,005$. Pendidikan kesehatan dengan media video tutorial penatalaksanaan ASI Ekslusif efektif meningkatkan pengetahuan dan keterampilan ibu dalam menyusui. Diharapkan dapat menggunakan video ini sebagai salah satu media dalam melakukan edukasi kepada ibu hamil dan ibu menyusui.

Kata kunci: video tutorial, ASI eksklusif

\section{PENDAHULUAN}

ASI eksklusif merupakan pemberian ASI (Air Susu lbu) sedini mungkin setelah persalinan yang diberikan tanpa jadwal dan bayi tidak diberikan makanan pendamping, meskipun hanya air putih sampai bayi berusia enam bulan. ${ }^{1}$ Menurut Riset kesehatan dasar (Riskesdas) tahun 2013, cakupan ASI eksklusif hanya sebesar 38\%, pencapaian tahun 2014 sebesar 54,3 \% dan tahun 2015 sebesar $55,7 \%$. Angka tersebut masih jauh dibawah target pemerintah yang menargetkan cakupan ASI eksklusif sebesar 80\%. Cakupan pencapaian pemberian ASI eksklusif di Jawa Barat tahun 2014 baru mencapai 33, $7 \%$, dan tahun 2015 sebesar $35,3 \%$. Angka tersebut masih jauh di bawah cakupan nasional. ${ }^{2}$

Rendahnya pencapaian tersebut dipengaruhi oleh banyak faktor salah satunya adalah rendahnya tingkat pemahaman ibu tentang pentingnya ASI selama 6 bulan pertama kelahiran bayi. ${ }^{3}$ Berbagai alasan dikemukakan oleh para ibu mengapa keliru dalam pemanfaatan ASI secara eksklusif kepada bayinya, antara lain adalah produksi ASI kurang, kesulitan bayi dalam menghisap, keadaan puting susu yang mendukung, ibu yang tidak menunjang, ibu bekerja, keinginan untuk disebut modern dan pengaruh iklan/promosi pengganti ASI dan tidak kalah pentingnya adalah anggapan bahwa semua orang sudah memiliki pengetahuan tentang manfaat $\mathrm{ASI}^{3}$ Suradi (2008) menyebutkan bahwa sering kali kegagalan dalam menyusui disebabkan karena kesalahan memposisikan dan melekatkan bayi. ${ }^{5}$ Hasil penelitian Puspita (2018) menyebutkan bahwa $61,9 \%$ ibu primipara masih belum tepat dalam melakukan teknik menyusui. Kesalahan banyak terletak pada posisi menyusui dan langkah-langkah menyusui. ${ }^{6}$

Untuk mencapai keberhasilan menyusui diperlukan pengetahuan mengenai penatalaksanaan pemberian ASI yang benar, seperti cara menyusui yang benar, cara memerah ASI, dan cara menyimpan ASI yang benar. Cara menyusui merupakan salah satu faktor yang mempengaruhi produksi ASI. Bila teknik dilakukan dengan tidak benar dapat menyebabkan puting menjadi lecet sehingga ibu merasakan perih dan enggan menyusui. Bahkan kondisi 
tersebut menjadikan bayi jarang menyusu yang akan berakibat kurang baik dalam pemenuhan nutrisi bayi. Sedangkan isapan bayi merupakan salah satu cara untuk merangsang produksi ASI pada ibunya. Pada faktanya sering kali ibu kurang mendapatkan informasi tentang manfaat ASI dan teknik menyusui yang baik dan benar. ${ }^{1}$

Petugas kesehatan bisa memberikan informasi tentang tentang penatalaksanaan pemberian ASI ekslusif dengan memberikan pendidikan kesehatan tentang cara menyusui yang benar, cara memerah dan menyimpan ASI yang benar. Petugas kesehatan harus meyakinkan ibu bahwa ibu menyusui bisa melakukan aktifitas lain yang harus meninggalkan bayinya di rumah bersama keluarga dengan tetap memberikan ASI. Ibu bisa melakukan pemerahan dan menyimpan stok ASI di lemari es. Oleh sebab itu ibu perlu dibekali keterampilan cara menyusui yang benar, cara memerah ASI dan menyimpan ASI yang benar.

Pada kenyataannya masih ada ibu yang tidak mengetahui cara menyusui yang benar, memerah dan menyimpan ASI yang benar. Hal ini menjadi kendala dalam pelaksanaan program ASI Eksklusif yang akan berdampak pada pemberian ASI dan menjadi penyebab utama terjadinya kegagalan menyusui. ${ }^{7}$ Penyuluhan kesehatan merupakan upaya untuk membekali pengetahuan dan keterampilan dalam penatalaksaaan pemberian ASI ekslusif. Lestari (2012) menyebutkan bahwa penyuluhan kesehatan tentang ASI ekslusif sudah sering dilakukan dibeberapa pelayanan kesehatan. Namun kenyataannya hal tersebut belum dapat meningkatkan pengetahuan serta kemampuan ibu dalam menyusui. ${ }^{8}$

Banyak metode dan media pendidikan kesehatan yang dapat digunakan dalam memberikan informasi kesehatan. Menurut
Juliantara (2009) dalam Lestari 2012 menyebutkan bahwa supaya pendidikan kesehatan yang diberikan lebih efektif dan sesuai sasaran serta tujuan, maka diperlukan media yang menarik dan lebih mudah diterima sasaran. Salah satu media yang dapat digunakan adalah video tutorial. Penggunaan media dalam memberikan informasi tentang pemberian ASI ekslusif dapat berpengaruh besar dalam penyerapan informasi yang disampaikan. Media video mengandalkan pendengaran dan penglihatan dari yang menerima. Media video melibatkan semua alat indra pembelajaran, semakin banyak alat indra yang terlibat untuk menerima dan mengolah informasi, maka semakin besar kemungkinan isi informasi tersebut dapat dimengerti dan dipertahankan dalam ingatan. ${ }^{7}$

Pendidikan kesehatan tentang penatalaksanaan ASI ekslusif dengan media video tutorial bertujuan untuk meningkatkan akselerasi pemikiran dan perasaan dengan sikap dan psikomotorik ibu menyusui. Selain itu dengan media video tutorial bisa memberi kesempatan berlatih menguasai keterampilan dalam penatalaksanaan pemberian ASI mulai dara teknik menyusui yang benar, cara memerah dan menyimpan ASI yang benar. Hasil penelitian Baharuddin (2014) menyebutkan bahwa hasil belajar peserta didik sebelum menggunakan video tutorial dalam kategori sangat rendah dan setelah menggunakan video tutorial berada pada kategori sedang, dengan normalisasi gainnya berada pada kategori sedang. Hal tersebut menunjukkan terdapat perbedaan ratarata minat peserta sebelum dan sesudah menerapkan media video tutorial. $^{9}$

Berdasarkan latar belakang tersebut sangat penting diketahui efektifitas media video tutorial pemberian ASI Ekslusif terhadap pengetahuan dan keterampilan ibu dalam menyusui. 


\section{METODE}

Desain penelitian yang digunakan adalah Quasi Eksperimen dengan NonRandomized Pre-Post Test group with control design, subjek penelitian dikelompokkan menjadi dua yaitu kelompok intervensi dan kelompok kontrol. Kelompok intervensi diberikan video tutorial tentang manajemen ASI eksklusif (cara menyusui, cara memerah ASI, dan cara menyimpan ASI). Selanjutnya dianalisa pengaruhnya terhadap peningkatan keterampilan ibu menyusui, kemudian dibandingkan dengan kelompok kontrol yaitu kelompok yang diberikan pendidikan kesehatan standar tanpa video tutorial.

Penelitian ini dilakukan di wilayah

Puskesmas Kota Bogor yang dilaksanakan pada bulan Mei November 2018. Kelompok intervensi dilakukan di Puskesmas Tanah Sareal dan Puskesmas Tegal Gundil, sedangkan kelompok kontrol dilakukan di Puskesmas Sindang Barang dan Sindang Sari. Besar sampel minimum dihitung menggunakan rumus quasi eksperimental design, sehingga diperoleh sampel minimal 26 pada kelompok intervensi dan 26 pada kelompok kontrol. Teknik pengambilan sampel dilakukan secara purposive sampling, dengan kriteria inklusi: Ibu menyusui dini (0-1 bulan), lbu menyusui bayinya (bayi sehat), Tidak ada kelainan dan dapat membawa bayinya ke tempat pertemuan, lbu dengan bayi yang memiliki belum terpapar susu formula.

Variabel yang diukur adalah keterampilan ibu dalam menyusui yaitu kemampuan responden melakukan teknik menyusui yang benar, cara memerah dan menyimpan ASI dengan baik, diperoleh melalui observasi, hasil pengukuran berupa skor pre dan post test. Untuk menganalisis perbedaan rata-rata keterampilan ibu menyusui yaitu tentang cara menyusui, cara memerah ASI dan cara menyimpan ASI sebelum dan sesudah intervensi diuji secara parametrik dengan uji tdependent.

Pengumpulan data primer menggunakan lembar observasi keterampilan pre-post. Kegiatan intervensi dilakukan dalam 2 kali pertemuan dan setiap pertemuan memakan waktu kurang lebih 60 menit.

\section{HASIL}

Berikut data hasil penelitian yang disajikan dalam bentuk narasi dan tabel:

Tabel 1 Distribusi Frekuensi Karakteristik Responden

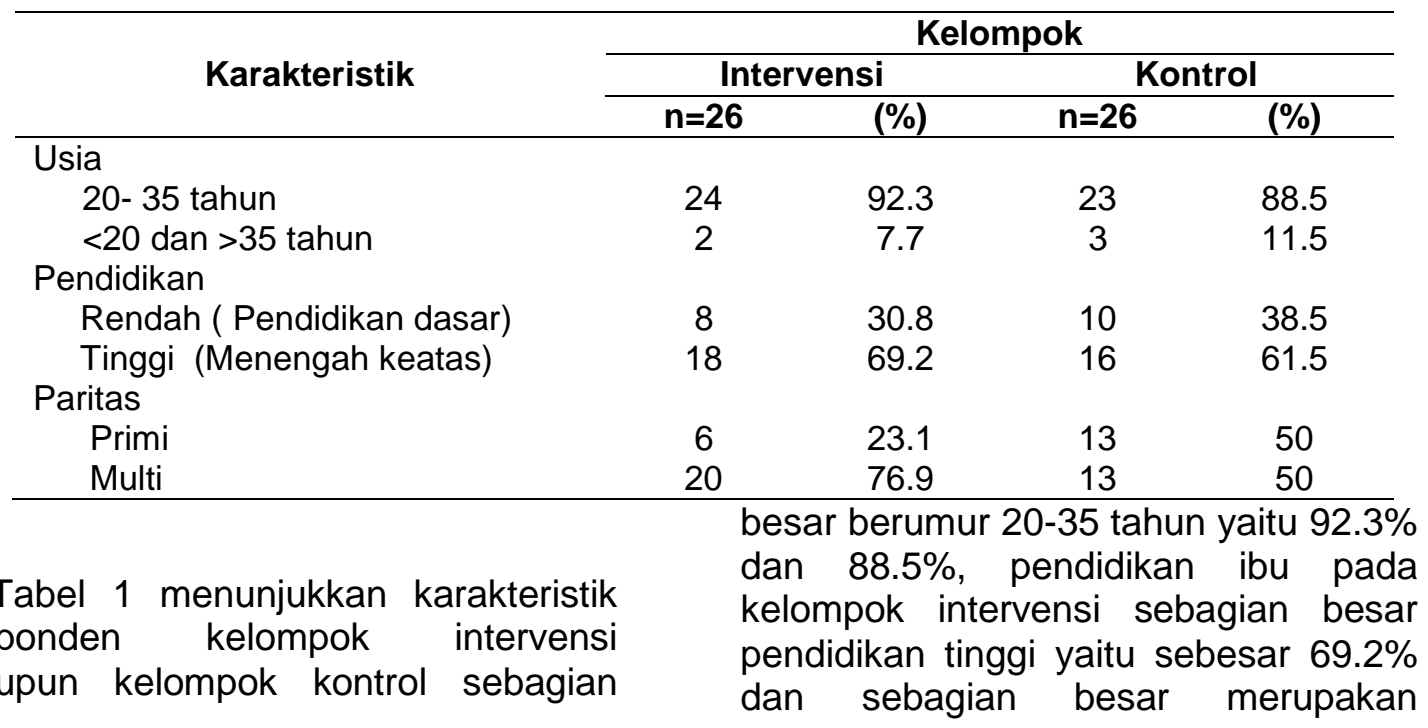


multipara (76.9\%), sedangkan kelompok kontrol yang berpendidikan berpendidikan tinggi (61.5\%) dan 50\% multipara.

Pada tabel 2 berikut menunjukkan video tutorial tentang penatalaksanaan ASI ekslusif efektif dalam meningkatkan pengetahuan dan keterampilan ibu dalam menyusui dengan nilai $(p<0.001)$, sedangkan pada 3 menunjukkan hasil analisis dengan menggunakan uji $t$ berpasangan untuk melihat perbedaan peningkatan keterampilan responden pada kelompok intervensi dan kelompok kontrol:

Tabel 2 Efektifitas Media Video Tutorial terhadap Keterampilan Responden

\begin{tabular}{ccccc}
\hline Variabel & & \multicolumn{2}{c}{ Kelompok Intervensi } & \\
\hline & Rerata (s.b) & Selisih (s.b) & Cl 95\% & Nilai p \\
\hline $\begin{array}{c}\text { Keterampilan } \\
\text { sebelum intervensi }\end{array}$ & $21.76(7.55)$ & & & \\
sesudah intervensi & $36.89(1.96)$ & & & \\
& & & & \\
\end{tabular}

Keterangan : $\mathrm{p}=$ Uji $\mathrm{t}$ berpasangan, selisih antara sesudah dan sebelum

Tabel 3 Perbedaan Peningkatan Keterampilan Responden Kelompok Intervensi dan Kontrol

\begin{tabular}{lcccc}
\hline \multicolumn{1}{c}{ Keterampilan } & n & Rerata (s.b) & Selisih Rerata (IK95\%) & Nilai p \\
\hline $\begin{array}{l}\text { Kelompok Intervensi } \\
\text { Kelompok Kontrol }\end{array}$ & 26 & $15.04(7.49)$ & $6.654(2.731-10.576)$ & 0.001 \\
& & $8.38(6.55)$ & & \\
\hline
\end{tabular}

Keterangan : p =Uji t tidak berpasangan

\section{PEMBAHASAN}

Berdasarkan hasil penelitian dapat diketahui bahwa terdapat peningkatan nilai rata-rata keterampilan responden pada kelompok intervensi antara sebelum dan sesudah diberikan edukasi dengan media video tutorial. Sebelum diberikan pendidikan kesehatan dengan media video tutorial tentang penatalaksanaan ASI ekslusif rata-rata keterampilan responden adalah 21.76 (7.554). Materi yang observasi untuk mengukur keterampilan ibu mengenai penatalaksanaan ASI ekslusif meliputi cara menyusui terdiri dari 10 pertanyaan, cara memerah dan menyimpan ASi sebanyak 11 pertanyaan.
Menyusui adalah suatu proses alamiah dan merupakan suatu seni yang harus dipelajari kembali. Ketidaktahuan ibu bagaimana cara menyusui yang baik dan benar akan berdampak pada pemberian ASI Eksklusif. Oleh karena itu diperlukan pengetahuan yang baik agar ibu mampu menyusui dengan benar. Salah satu upaya untuk meningkatkan pengetahuan ibu bagaimana cara menyusui yang benar adalah dengan cara diberikan pendidikan kesehatan. Pendidikan kesehatan ini disampaikan menggunakan media video tutorial bagaimana penatalaksanaan pemberian $\mathrm{ASI}$ eksklusif mulai dari cara menyusui yang benar, cara memerah dan menyimpan ASI.

Hasil penelitian ini diperoleh peningkatan nilai rata-rata keterampilan 
ibu dalam menyusui setelah diberikan pendidikan kesehatan dengan media video tutorial tentang cara menyusui yang benar, cara memerah dan menyimpan ASI. Hasil ini sesuai dengan hasil penelitian Lestari (2012) yang menyebutkan bahwa pendidikan kesehatan tentang ASI dengan menggunakan media audiovisual efektif terhadap peningkatan pengetahuan, kemampuan dan motivasi menyusui. ${ }^{8}$ Begitu pula hasil penelitian Wahyuningsih (2017) yang menyebutkan bahwa pendidikan kesehatan dengan media video efektif meningkatkan pengetahuan tentang perawatan payudara. ${ }^{10}$

Pendidikan kesehatan yang diberikan hans lebih efektif dan sesuai sasaran serta tujuan, maka diperlukan media yang menarik dan lebih mudah diterima oleh sasaran. Salah satu media yang dapat digunakan dalam melakukan pendidikan kesehatan mengenai cara menyusui yang benar adalah media audiovisual. Media audiovisual mengandalkan pendengaran dan penglihatan dari sasaran. Penggunaan audiovisual melibatkan semua alat indra pembelajaran, oleh karena itu, maka semakin banyak alat indra yang terlibat untuk menerima dan mengolah informasi, semakin besar kemungkinan isi informasi tersebut dapat dimengerti dan dipertahankan dalam ingatan. Media audiovisual yang lebih menonjolkan fungsi komunikasi diantaranya film, cerita, iklan, dan video. ${ }^{7}$

Penyuluhan kesehatan tentang ASI eksklusif sudah sering dilakukan dibeberapa pelayanan kesehatan. Namun kenyataannya hal tersebut belum dapat meningkatkan pengetahuan serta kemampuan ibu dalam menyusui. Pendidikan kesehatan yang diberikan agar dapat mencapai tujuan harus memperhatikan beberapa hal diantaranya adalah materi atau pesan dan metode yang disampaikan.
Materi atau pesan yang disampaikan harus memperhatikan beberapa hal diantaranya adalah menggunakan bahasa yang mudah dimengerti oleh masyarakat dalam bahasa kesehariannya, materi atau pesan tidak terlalu sulit dimengerti oleh sasaran, dalam penyampaian materi sebaiknya menggunakan media agar menarik perhatian sasaran, dan materi disampaikan merupakan kebutuhan dasar dalam masalah kesehatan yang dihadapi sasaran. ${ }^{11}$

Hasil penelitian ini juga sesuai hasil penelitian yang dilakukan oleh Lopez dalam Lestari (2012) yang menyebutkan bahwa terdapat perbedaan peningkatan pengetahuan antara kelompok yang diberikan pendidikan kesehatan melalui media audiovisual. Begitu pula menurut Dwyer dalam Lestari (2012), video mampu menyita $94 \%$ saluran masuknya pesan atau informasi ke dalam jiwa manusia melalui mata dan telinga, serta mampu untuk membuat orang mengingat $50 \%$ dari apa yang mereka lihat dan dengar dari tayangan program. Materi atau pesan yang disampaikan melalui video dapat mempengaruhi emosi yang kuat dan juga dapat mencapai hasil cepat yang tidak dimiliki oleh media lain. ${ }^{7}$

Hasil penelitian ini diperoleh peningkatan skor keterampilan ibu dalam menyusui setelah diberikan pendidikan kesehatan melalui media video tutorial. Hal tersebut menunjukkan bahwa media video lebih banyak keuntungan di antaranya dapat di lakukan secara berulangulang, mempersingkat waktu dan mudah di ingat. Media video adalah media yang dapat menyajikan informasi, menggambarkan suatu proses dan tepat mengajarkan keterampilan, menyingkat dan mengembangkan waktu dan mempengaruhi sikap, salah satu media yang berbasis Audio visual yang dapat diberikan guru dalam proses pembelajaran agar 
pembelajaran menjadi lebih mudah dan meningkatkan minat siswa, Video juga dapat menyajikan informasi, menggambarkan suatu proses dalam waktu singkat.

Hasil penelitian ini didukung oleh hasil penelitian Himawati (2011) yang menyebutkan bahwa terdapat peningkatan perilaku menyusui ibu primipara setelah diberi pendidikan kesehatan tentang teknik menyusui. Setelah diberi pendidikan kesehatan terdapat perubahan perilaku dalam menyusui sebesar 4,23. Dengan demikian, pemberian pendidikan kesehatan tentang teknik menyusui telah meningkatkan keterampilan perilaku ibu primipara dalam menyusui bayinya di BPS Kecamatan Kalibawang Kulonprogo. ${ }^{12}$

Penelitian lain yang dilakukan Zulkarnain (2011) menyebutkan bahwa setelah diberikan penyuluhan dengan menggunakan Video, maka pengetahuan dan sikap responden meningkat dari 1 responden yang memiliki pengetahuan tinggi (4\%) menjadi 21 responden yang berpengetahuan tinggi $(87,5 \%)$ dan dari 14 responden yang sikapnya mendukung $(58,3 \%)$ menjadi 24 responden yang memiliki sikap mendukung dalam Inisiasi Menyusu Dini (IMD). ${ }^{13}$

Tujuan diberikannya pendidikan kesehatan adalah untuk mengubah perilaku seseorang atau masyarakat dari perilaku yang tidak sehat menjadi perilaku yang sehat. Teori Edgar Dale, media pendidikan kesehatan dengan menggunakan video yang masih dalam jenis film berada dalam lapisan ke 4 . Lapisan ke empat menunjukkan bahwa dengan media video, pesan dapat dengan mudah diterima oleh sasaran dan lebih efektif dibandingkan dengan menggunakan tulisan dan gambar. Dengan media video sasaran akan menggunakan 2 indera yaitu indera penglihatan dan indera pendengaran dalam menerima informasi. ${ }^{14}$

Pengamatan pada suatu objek dengan menggunakan banyak indera, akan membuat seseorang tersebut semakin jelas dan mudah dalam menerima informasi yang diterimanya. Media video memiliki kelebihan yaitu memanipulasi suatu waktu dan kondisi bahkan ruang yang dapat membantu seseorang melihat dan mengetahui suatu kejadian yang sudah terjadi bahkan yang belum terjadi. ${ }^{13}$ Penggunaan media video dalam penelitian ini sangat membantu dan mempermudah responden untuk melihat dan memahami bagaimana berperilaku yang baik dan benar dalam memberikan Air Susu Ibu kepada bayinya yaitu cara menyusui yang benar, cara memerah dan menyimpan ASI perah.

Dari uraian di atas dapat diketahui bahwa video tutorial mengenai pemberian ASI eksklusif yang meliputi cara menyusui yang benar, cara memerah dan menyimpan ASI yang benar dapat menjadi media untuk mendapatkan pengetahuan tentang pemberian ASI eksklusif sehingga ketrampilan ibu dalam pemberian ASI eksklusif tersebut meningkat. Dari hasil penelitian diketahui bahwa video tutorial tentang penatalaksanaan ASI eksklusif yaitu mengenai cara menyusui, cara memerah dan menyimpan ASI efektif dalam meningkatkan pengetahuan dan keterampilan ibu dalam menyusui.

Hasil penelitian Lestari (2013) menunjukkan bahwa terdapat hubungan yang bermakna antara tingkat pengetahuan ibu tentang ASI dengan pemberian ASI Eksklusif. ${ }^{8}$ Tujuan pendidikan kesehatan bertujuan agar peserta didik dapat memiliki pengetahuan tentang ilmu kesehatan, nilai dan sikap yang positif terhadap hidup sehat, keterampilan dalam melaksanakan kegiatan yang berkaitan dengan perawatan kesehatan 
dan memiliki kebiasaan yang sehat dalam kehidupan sehari-hari.

Dalam penelitian ini peneliti berpendapat bahwa edukasi kesehatan dengan metode video sangat efektif dalam peningkatan pengetahuan ibu menyusui tentang bagaimana cara menyusui yang benar, bagaimana cara memerah dan menyimpan ASI, hal tersebut akan sangat menunjang untuk memberikan ASI secara ekslusif. Metode video ini yang lebih menarik membantu responden dalam penyerapan informasi. Informasi yang disuguhkan lewat video juga lebih mudah didapatkan karena para responden bisa melihat kembali edukasi yang diberikan lewat handphone sewaktu-waktu jika diperlukan.

Pengetahuan sesorang dapat mendasari sikap dan keterampilan sehingga dapat bertahan lebih lama daripada yang tidak didasari oleh pengetahuan, sehingga perlu dilakukan peningkatan pengetahuan dengan harapan sikap dan keterampilan bisa menjadi lebih baik. Oleh karena itu perlu dilakukan promosi kesehatan tentang penatalaksanaan pemberian ASI ekslusif pada ibu dengan cara memberikan informasi melalui media yang tepat, sehingga pengetahuan dan keterampilan ibu menyusui meningkat dan perilaku pemberian ASI ekslusif semakin membaik. Pendidikan responden pada penelitian ini sebagian besar berpendidikan SMA. Besar atau sedikitnya pengetahuan yang didapat individu baik melalui pendidikan formal maupun informal memiliki kontribusi yang besar terhadap individu dalam pengambilan keputusan untuk berperilaku hidup sehat, yang memiliki dampak langsung terhadap status kesehatan.

\section{SIMPULAN}

Berdasarkan hasil penelitian dan pembahasan maka dapat ditarik kesimpulan bahwa keterampilan ibu menyusui mengalami peningkatan skor rata-rata sesudah diberikan pendidikan kesehatan dengan media video tutorial penatalaksanaan ASI Ekslusif (cara menyusui yang benar, cara memerah dan menyimpan ASI). Pendidikan kesehatan dengan media video tutorial penatalaksanaan ASI Ekslusif (cara menyusui yang benar, cara memerah dan menyimpan ASI) efektif meningkatkan keterampilan ibu dalam menyusui.

\section{UCAPAN TERIMAKASIH}

Ucapan terimakasih penulis sampaikan kepada Dinas Kesehatan Kota Bogor khususnya lokasi tempat pengambilan data yaitu puskesmas Tanah Sareal, Tegal Gundil, Sindang Barang, dan Sindang Sari Kota Bogor yang telah memberikan kesempatan kepada penulis untuk melakukan penelitian di wilayah ini, dan terimakasih penulis ucapkan kepada Poltekkes Kemenkes Bandung yang telah membiayai pelaksanaan penelitian ini dan para reviewer saat proses penelitian maupun penerbitan artikel ini.

\section{DAFTAR RUJUKAN}

1. Roesli U. Mengenal ASI Eksklusif. Jakarta: Trubus Agriwidya; 2013.

2. Kementerian Kesehatan RI. Pedoman umum program Indonesia sehat dengan pendekatan keluarga. Jakarta: Kemenkes Republik Indonesia; 2015.

3. Kementerian Kesehatan Republik Indonesia. Riset kesehatan dasar (Riskesdas) 2013. Jakarta: Badan Penelitian dan Pengembangan Kesehatan Kementerian Kesehatan RI; 2013

4. Kemenkes RI, Pusat data dan situasi kementerian kesehatan RI : situasi dan analisis ASI eksklusif, 2014

5. Suradi, $\mathrm{R}$ dan Hegar. Indonesia Menyusui. Jakarta: IDAI;2010.

6. Puspita Andini. Hubungan Pelaksanaan 10 Langkah Menuju Keberhasilan Menyusui Dengan Cakupan ASI 
Eksklusif di Kota Kenfari. J Ilm Kesehat Diagnosa. 2018;12(6):686-695.

7. Lestari W, Amelia N.K., Rahmalia S. Efektifitas pendidikan kesehatan tentang ASI terhadap tingkat pengetahuan, kemampuan, dan motivasi menyusui primipara. Jurnal Ners Indonesia. Vo.2, No.2, Maret 2012. Hal:192-199

8. Lestari D, Zuraida R, Larasati TA. Hubungan tingkat pengetahuan ibu tentang air susu ibu dan pekerjaan ibu dengan pemberian ASI ekslusif di Kelurahan Fajar Bulan. Medical Journal of Lampung University Vol. 2, No.4, Februari; 2013. Hal: 88-99

9. Baharuddin Ilham. Efektivitas penggunaan media video tutorial sebagai pendukung pembelajaran matematika terhadap minat dan hasil belajar peserta didik SMA Negeri 1 Bajo Kabupaten Luwu Sulawesi Selatan. Jurnal Nalar Pendidikan. Volume 2, nomor 2, JuliDesember 2014

10. Wahyuningsih W, Rizky F. Health Education with Slide Media and Effective Videos Increase Knowledge about Breast Care. J Ners dan Kebidanan Indones. 2019;6(3):21. doi:10.21927/jnki.2017.5(3).39-44
11.Mubarak WI. Promosi Kesehatan Sebuah Pengantar Proses Belajar Mangajar dalam Pendidikan. Yogyakarta: Graha Ilmu; 2007.

12. Himawati L, Mawarti R. Pengaruh pendidikan kesehatan tentang teknik menyusui terhadap pengetahuan dan perilaku teknik menyusui pada ibu primipara di BPS Kecamatan Kalibawang Kulonprogo. Published online 2011.

13.Zulkarnain E Yusi L dan Farida N, Efektifitas antara metode penyuluhan dengan flipchart dan menggunakan video compact disc dalam meningkatkan pengetahuan dan sikap ibu hamil terhadap inisiasi menyusu ini; 2011 vol. 1, No 2, Hal 44-53.

14.Notoatmodjo, Soekidjo. Kesehatan Masyarakat Ilmu dan Seni. Jakarta : Rineka Cipta; 2011. 